\title{
Effect of microwave on some electrical properties of wet bones
}

\author{
Ayman A. Alhashmee \\ Physiology Department \\ Collage of Medicine \\ University of Mosul
}

\author{
Qusay Kh. Omer Al-Dulamey \\ Physics Department \\ College of Science \\ University of Mosul
}

\section{Tymaa Noori Alglami \\ Physiology Department / Collage of Medicine \\ University of Mosul}

Received

$23 / 11 / 200^{\wedge}$
Accepted

25 / 02 / 2009

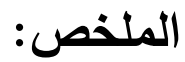

في هذا البحث نم دراسة تأثير الموجات الدقيقة على بعض الخواص الكهربائية لعظام

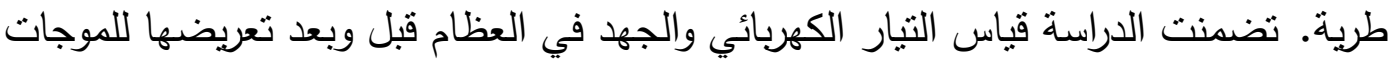
الدقيقة. ان طاقة الموجات الدقيقة التي استخدمت للتشعيع هي .9 و ـ11 واط وبتردد مقداره

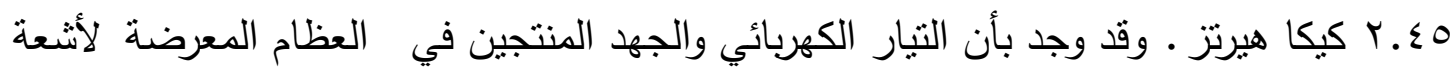

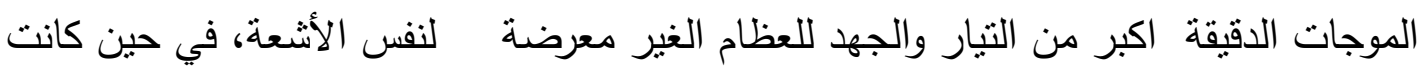

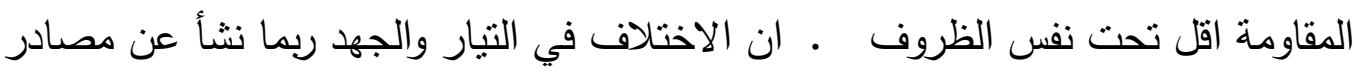

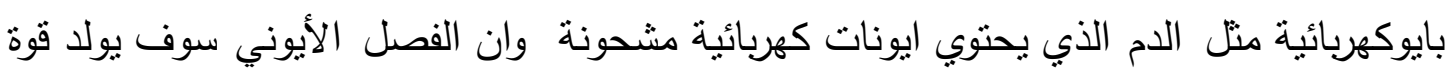
كهروداينمكية والتي تلكّون فولتية بين نقطتين في العظام الطرية.

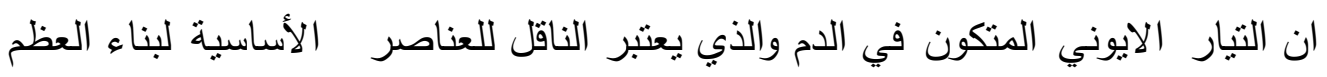

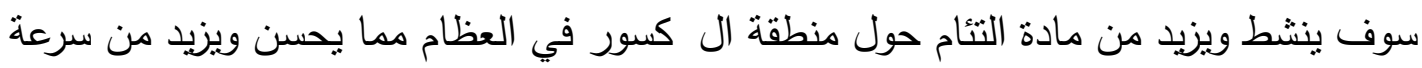
الثنفاء.

\section{Abstract:}

In this research we have to study the effect of microwave radiation on some electrical properties of the wet bone, it is included to measure the electrical current and potential in bones before and after exposure to microwave radiation. The microwave uses a near-field focused energy 
(90-180 watts at $2.45 \mathrm{GHz}$ frequency). Its found that the value of electrical current and potential produced in the bone exposed to microwave radiation are more than the value of electrical current and potential for unexposure bones, while the resistance is less under the same conditions. These differences in current and potential may be attributed for bioelectrical sources such as blood which contains electrically charged ions and the separation of ionic charges will produce an electromotive force, which is a voltage between points in fresh bone.

The generated ionic current in blood which regarded carrier of the basic elements to buildup of bone will stimulate and increase the callus material around the fractures in bones and hence improves and speeds its healing.

\section{Introduction:}

Bone is an extremely complex in terms of chemistry, biology, and mechanics, and it has a very variable structure depending on its position and purposes. Living bones manifest several types of bioelectric potentials are attributed to the blood flow and consequent ionic separation while others are related to the release and inhibition of amines and biochemical activities.

McMeeken and Bell, 1990 notice the doses of microwave irradiation to the hindlimb of the anaesthetized dog increased the temperature in the underlying skin and muscle by 5-6 degrees $\mathrm{C}$ and, after a latency of 2-8 min, heart rate, blood pressure and femoral conductance all increased. And conclusion of irradiation, heart rate and blood pressure rapidly returned to basal levels, but there was a sustained increase in femoral conductance which was mainly in the leg.

Arshak and Anaz, 1991 investigated some electromechanical properties of wet and dry bones, where claimed that the electrical current and potential produced for loaded bones are more than the current and potential for unloaded bones. They carried out some investigation on the electromechanical behavior of bones.

The primary therapeutic effects take place in a heated area are the increase in metabolism resulting in a relaxation of the capillary system and the increase in blood flow. the relaxation and the increase in blood flow are beneficial to damaged tissue, (Cameron and Skofronick, 1992).

The frequency used in microwave diathermy is $2450 \mathrm{MHz}$ because this frequency was the one available after world II, this is unfortunate since later research has shown that a frequency closer to $900 \mathrm{MHz}$ would bo more effective in therapy, causing more uniform heating around bony regions (Cameron and Skofronick, 1992). 
Microwave interactions with biological tissues were studied during the last several years (Gazelle'et al, 2000). The main mechanism of heating occurs as a result of rotation of water molecules brought about by the microwaves. Water is a molecule which is unevenly charged along its structure, being more negatively charged in some parts of the molecule and more positively charged in others. Such molecules are called "dipoles". When exposed to an electromagnetic field, dipoles behave as if they are tiny magnets and try to line up with it. The electromagnetic field generated in a microwave oven oscillates with a frequency of $2450 \mathrm{MHz}$ (or 2450 million cycles per second), so these dipoles (or molecular magnets) have to move back and forth at a speed of over two thousand million times a second to follow the field as figure (1) (Hill,1998). Energy is absorbed in this process affecting the molecules themselves and their interactions with neighboring molecules.

The interaction between microwave and tissues include heat generation by resistive losses of moving charged-ions and oscillations of charged molecules, and heat transfer by induced movements of charged ions.
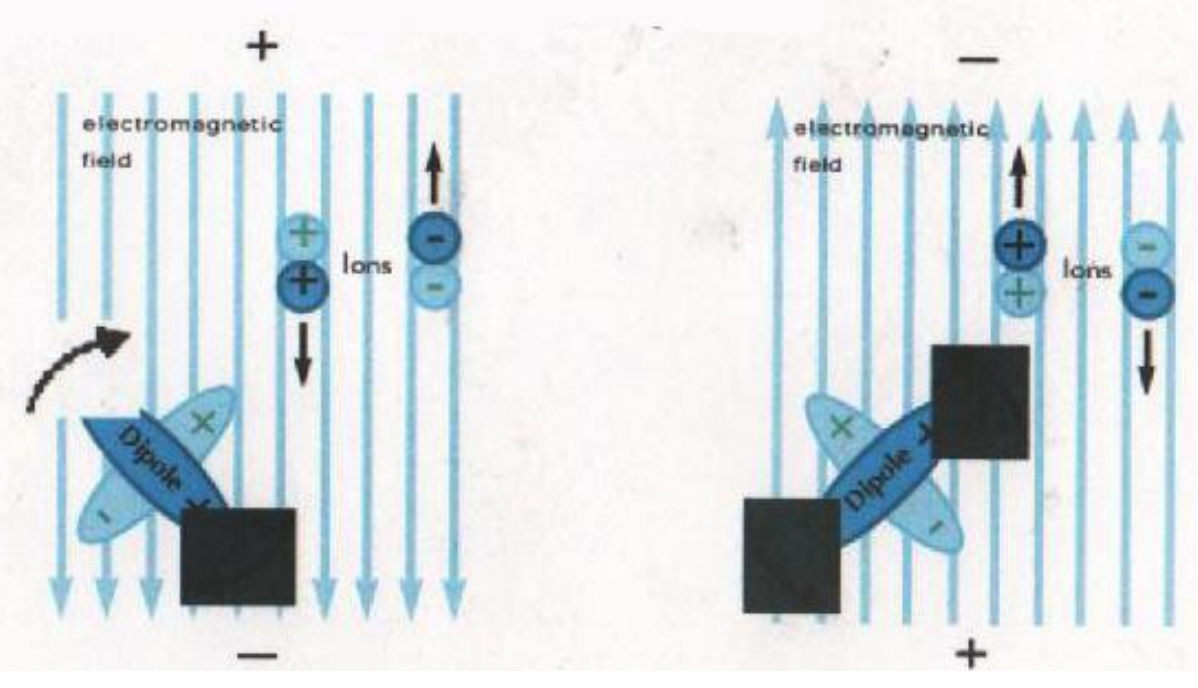

Figure (1): Movement of dipoles and ions due to oscillating electromagnetic field (Hill,1998)

At temperatures over $50^{\circ} \mathrm{C}$, tissues undergo vaporization and carbonization. Higher temperatures may cause desiccation, protein denaturation, coagulation and finally welding and cavitation (Eshet et al, 2004 ) (Gazelle`et al, 2000).

Blood, like all tissues, contains electrically charged ions. A physics principle known as Faraday's Law states that a magnetic field will exert a force on a moving ionic current. Furthermore, an extension of Faraday's 
law called the Hall effect states that when a magnetic field is placed perpendicular to the direction of flow of an electric current, it will tend to deflect and separate the charged ions. While the deflection of ions will be in opposite directions depending on the magnetic pole encountered and the charge of the ion, this force is not based on the attraction or repulsion of like and unlike charges (Porter, 1997).

(Eshet et al, 2004) study of drilling in fresh wet bone tissue in vitro using the microwave drill method toward testing its applicability in orthopaedic surgery. Where used microwave drill a near-field focused energy under $200 \mathrm{~W}$ at $2.45 \mathrm{GHz}$ frequency in order to penetrate bone in a drilling speed of $1 \mathrm{~mm} / \mathrm{s}$, and showed that the microwave drill produces substantially smoother holes in cortical bone than those produced by a mechanical drill.

(Copty et al, 2004) were used $9 \mathrm{GHz}$ near-field microwave probe for local surface heating of microwave absorbing materials. The microwave energy is concentrated in a small region close to the applicator, in such a way that the microwave intensity there is very high. They emphasize results on local heating and coagulation of egg-white and albumin which may be used as a "biological solder" for tissue welding applications.

\section{The objective :}

To study the effect of microwave radiation on some electrical properties of the wet bone. The generated ionic current (according to the Hall effect, when a magnetic field is placed perpendicular to the direction of flow of an electric current, it will tend to deflect and separate the charged ions) will stimulate and increase the callus material around the fractures in bones and hence improves and accelerate the healing.

\section{Materials and method :}

Several wet ovine femoral bones are prepared by cleansing them and removing the skin. the probes are inserted in holes previously made in the sample at regular distance of about three centimeters (this distance selected because the samples were have different volumes), for measurement purposes. The bones irradiated by microwave oven with energy (90 and 180 watts at $2.45 \mathrm{GHz}$ frequency) for a several times $(10,20,30,40,50,60)$ second. Samples have been linked to a simple electric circuit adopt the principle of Ohm's Law, as shown in Figure (2). The current passing through the sample was recorded using microameter, while the sample potential also measured by voltmeter at the same time with accuracy of $10^{-3}$ volt. 


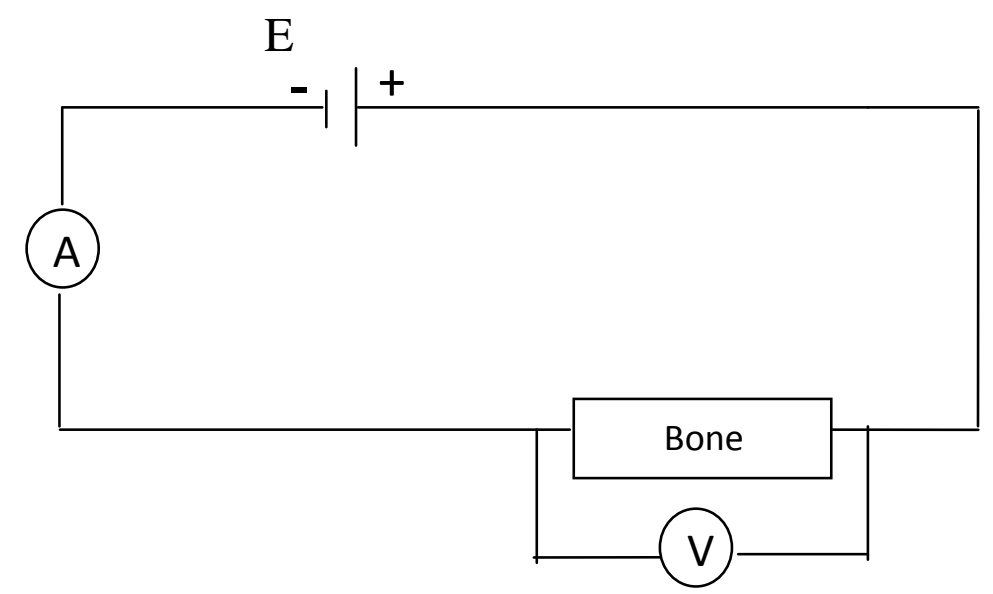

Figure (2): the electric circuit which used to measure the current and potential passing through the bone

The current and potential for wet bones were obtained before and after exposure to microwave. the current and potential for irradiated bone were obtained after its eliminating from oven directly.

\section{Results and Discussion :}

The age of ovine femoral bones used was about 5 to 10 months. the current and potential are measured before and after irradiation by the microwave at 90 and 180 watts with various times.

Table (1) and (2) shows the data recorded for the current and potential difference before and after supplied to microwave at 90 and 180 watts while the resistance was estimate theoretically.

Table (1): the data recorded for the current and potential difference before and after supplied to microwave at power 90 watts.

\begin{tabular}{|c|c|c|c|c|}
\hline & $\begin{array}{c}\text { Current } \\
(\mathbf{I} / \mathbf{m A})\end{array}$ & $\begin{array}{c}\text { voltage } \\
\text { (v/volt) }\end{array}$ & $\begin{array}{c}\text { Resistance } \\
\text { (K-Ohm) }\end{array}$ & Time (sec) \\
\hline Before irradiation & 0.100 & 4.9 & 49 & 0 \\
\hline \multirow{4}{*}{ After irradiation } & 0.100 & 4.9 & 49 & 10 \\
\cline { 2 - 5 } & 0.105 & 5.1 & 48.5 & 20 \\
\cline { 2 - 5 } & 0.107 & 5.2 & 48.5 & 30 \\
\cline { 2 - 5 } & 0.111 & 5.3 & 47.7 & 40 \\
\cline { 2 - 5 } & 0.147 & 5.4 & 36.7 & 50 \\
\cline { 2 - 5 } & 0.150 & 5.6 & 37.3 & 60 \\
\hline
\end{tabular}

Table (2): the data recorded for the current and potential difference before and after supplied to microwave at power 180 watts

\begin{tabular}{|c|c|c|c|c|}
\hline & $\begin{array}{c}\text { Current } \\
(\mathbf{I} / \mathbf{m A})\end{array}$ & $\begin{array}{c}\text { voltage } \\
(\mathbf{v} / \text { volt) }\end{array}$ & $\begin{array}{c}\text { Resistance } \\
(\mathbf{K}-\mathbf{O h m})\end{array}$ & Time (sec) \\
\hline Before irradiation & 0.100 & 4.9 & 49 & 0 \\
\hline \multirow{4}{*}{ After irradiation } & 0.105 & 5.2 & 49.5 & 10 \\
\cline { 2 - 5 } & 0.110 & 5.3 & 48.1 & 20 \\
\cline { 2 - 5 } & 0.175 & 5.8 & 33.1 & 30 \\
\cline { 2 - 5 } & 0.200 & 5.9 & 29.5 & 40 \\
\cline { 2 - 5 } & 0.250 & 6.2 & 24.8 & 50 \\
\cline { 2 - 5 } & 0.300 & 6.3 & 21 & 60 \\
\hline
\end{tabular}


Figure (3) and (4) shows a comparison between current and voltage values at the power 90 and 180watts. It's clear from two figures that the current and voltage increased with exposure time of microwave while the resistance is decreases with exposure time as shown in figure (5). The decreases of bone resistivity $(\rho)$ with high temperature leads to increasing the conductivity $(\sigma)$ of bone where:

$$
\sigma=1 / \rho
$$

When the temperature of bone is high as result to irradiation by microwave, this leads to decreases in resistivity and increasing in conductivity of bone and caused increasing in the current. The increasing in current and voltage was also producing When a electromagnetic field is placed over a blood vessel, the influence of the field will cause positive and negative ions (for example, $\mathrm{Na}+$ and $\mathrm{Cl}-$ ) to bounce back and forth between the sides of the vessel, creating flow currents in the moving blood. The combination of the electromotive force, altered ionic pattern, and the currents causes blood vessel dilation with a corresponding increase in blood flow (Porter, 1997). the heat generation by resistive losses of moving charged-ions and oscillations of charged molecules, and heat transfer by induced movements of charged ions may be also lead to increase the voltage and current, and might also be attributed to the change in blood composition as result to the change in crystal structure of blood after exposure to microwave.

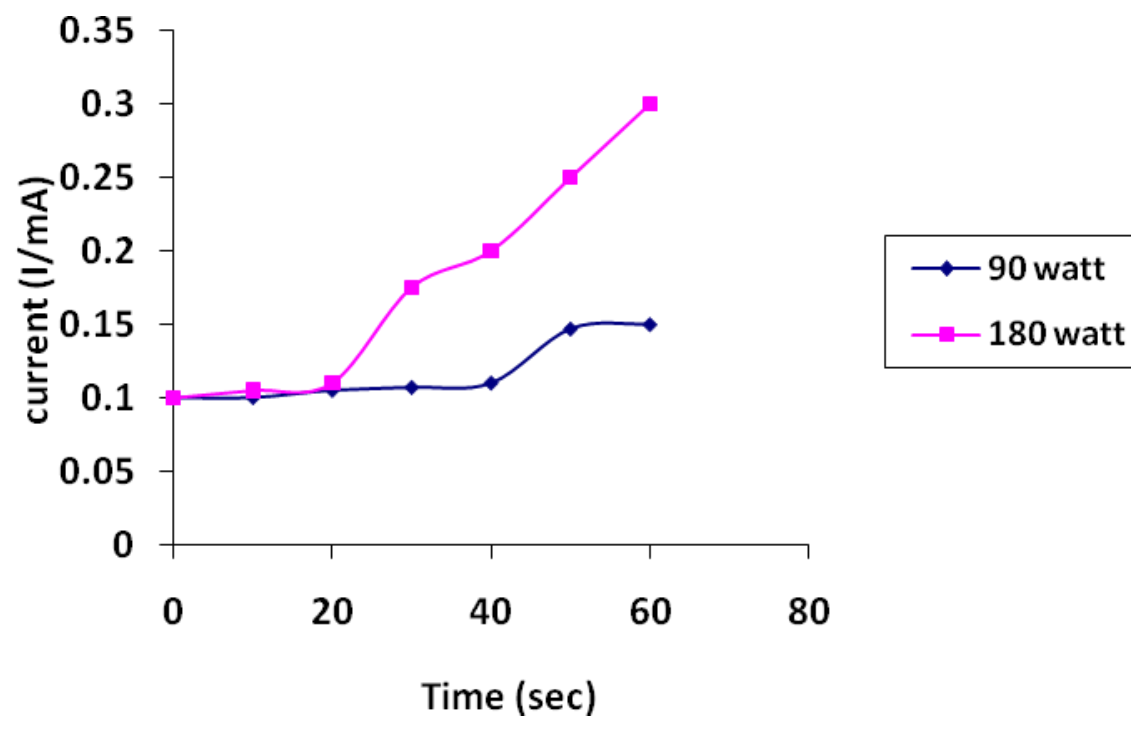

Figure (3): the relation between current and time of irradiation of microwave at powers 90 and 180 watts 


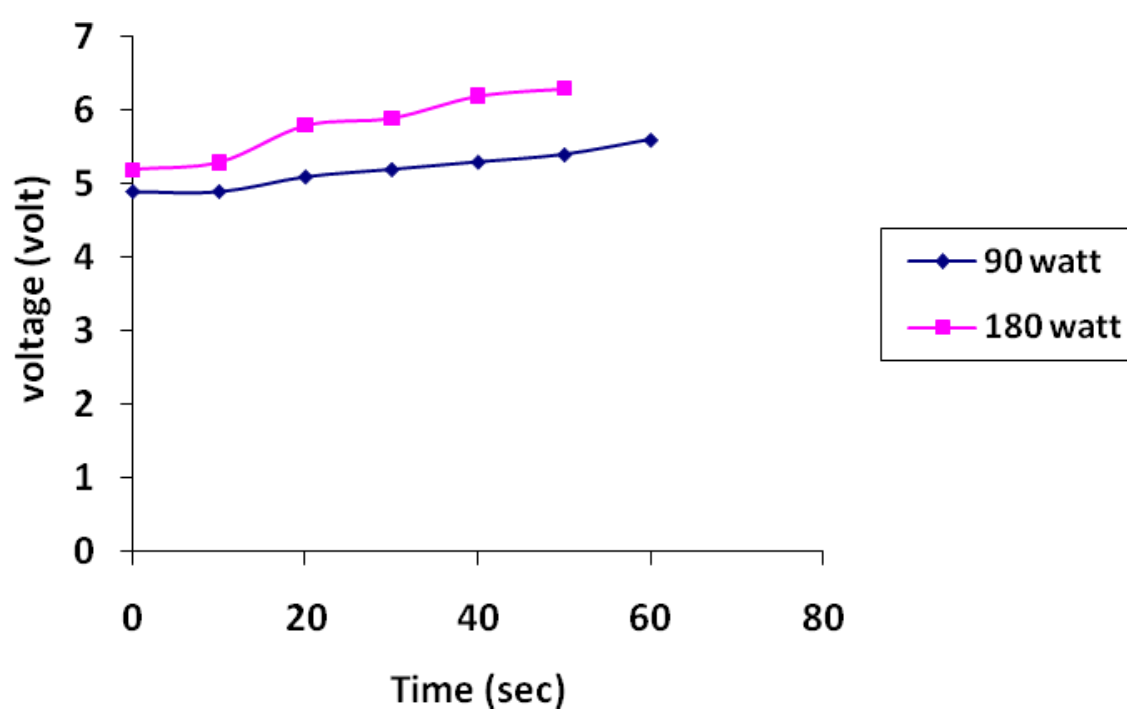

Figure (4): the relation between voltage and time of irradiation of microwave at powers 90 and 180 watts

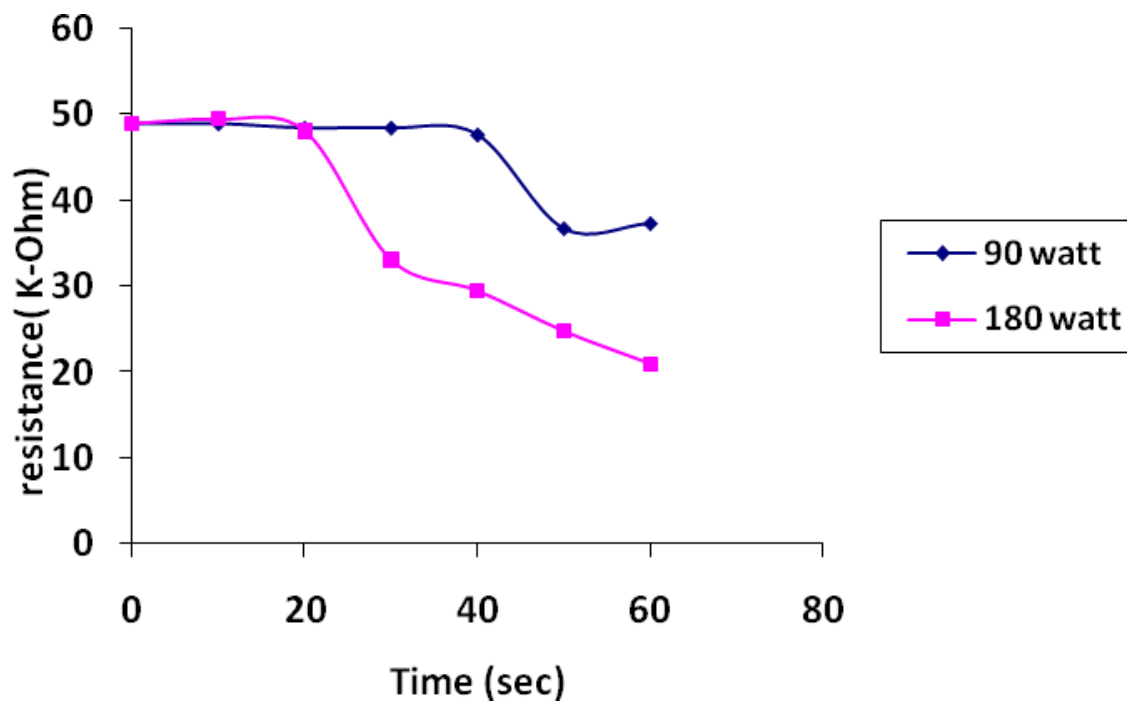

Figure (5): the relation between resistance and time of irradiation of microwave at powers 90 and 180 watts

The current and the potential for irradiated bone at 180 watts and period 60 second was greater than that for non irradiated bone by about 50 and 35 percent respectively.

\section{Conclusion :}


As a result of the research work described in this paper, supply of microwave to the bone effects on the generated current and potential of the bone. Its believed that the results presented in this research work might give a new aid and information to the bone healing problems when the microwave is used.

\section{Reference :}

1) McMeeken, JM and Bell, C, (1990), Effects of microwave irradiation on blood flow in the dog hindlimb, Experimental Physiology, Vol. 75, Issue 3, 367-374

2) Arshak, Kh and Anaz, M, (1991), Electricity in Bones, Annals of college of medicine mosul, vol. 17, no. 1

3) Cameron, Jo and Skofronic, Ja, (1992), Medical physics, John Wiley and Sons, pp.74-76.

4) Porter, M., (1997), Magnetic Therapy, Equine Vet Data, 17(7): 371.

5) Hill, Al, (1998), Microwave Oven, International Life Sciences Institute, pp.1-3.

6) Gazelle, G., Goldberg, S., Solbiati, L., and Livraghi, T., (2000), Tumor ablation with radio-frequency energy, Radiology, vol. 217, pp. 633-646.

7) Eshet, Y., Mann, R., Anaton, A., Yacoby, To., (2004), Microwave Drilling of Bones, Biomedical Engineering, IEEE Transactions on Volume PP, Issue 99, Page(s): 1 - 1

8) Copty, A., Sakran, F., Golosovsky, M. and Davidov, D., (2004), Low-power near-field microwave applicator for localized heating of soft matter, Appl. Phys. Lett. 84, 5109 (2004); DOI:10.1063/1.1763213. 